\title{
O DIREITO FUNDAMENTAL À LIBERDADE - OS LIMITES PARA O DESENVOLVIMENTO E A TEORIA DO DECRESCIMENTO
}

\section{THE FUNDAMENTAL RIGHT TO FREEDOM - THE LIMITS FOR DEVELOPMENT AND THE DECREASE THEORY}

\author{
Walkiria Martinez Heirinch Ferrer ${ }^{1}$ \\ Regina Célia de Carvalho Martins ${ }^{2}$
}

\section{RESUMO}

O presente estudo objetiva abordar o direito à liberdade consagrado como um dos direitos fundamentais pela Constituição, sob o aspecto "liberdade de escolha", frente à sociedade de consumo e ao fenômeno da globalização, em que tal liberdade, se mostra manipulada pelos grandes especuladores do mercado econômico. A escolha do tema se justifica diante do crescente quadro de desigualdade social atualmente observado e seu impacto no desenvolvimento. Busca-se com o presente trabalho um estudo mais detalhado sobre o direito à liberdade e seus aspectos, bem como as adaptações exigidas em prol do desenvolvimento. No primeiro tópico é efetuada uma análise do direito à liberdade, como proposto pela doutrina Constitucional, para no momento seguinte, estudar-se o mesmo sob a perspectiva do desenvolvimento, com ênfase na Teria do Decrescimento, proposta pelo filósofo e economista Serge Latouche. Em conclusão, é possível observar que um olhar crítico sobre o direito à liberdade se faz necessário, isto porque a visão disseminada no mundo globalizado gera a falsa noção de que abundância econômica gera "bem-viver" e liberdade, mas, em verdade, urge uma reavaliação dos limites do direito fundamental à liberdade e o seu efetivo alcance no cenário jurídico econômico atual.

Palavras-chave: Direito fundamental à liberdade. Liberdade de escolha. Especulação no mercado econômico. Teoria do decrescimento. Serge Latouche.

\begin{abstract}
This study aims to address the right to liberty enshrined as one of the fundamental rights by the Constitution, under the aspect of "freedom of choice", against the consumer society and the phenomenon of globalization, in which such freedom is manipulated by the great speculators of the economic market. The choice of theme is justified by the growing picture of social inequality currently observed and its impact on development. The present work

\footnotetext{
${ }^{1}$ Mestre e Doutora em Educação pela UNESP/Marília - Graduação em Ciências Sociais pela UNESP/Marília. Professora do Programa de Doutorado e Mestrado em Direito da UNIMAR. Pró Reitora de graduação da UNIMAR Título e Resumo. Universidade de Marília - UNIMAR, São Paulo - Brasil. E-mail: walkiriamf@terra.com.br

${ }^{2}$ Mestre e Doutoranda em Direito pela UNIMAR - Universidade de Marília. Professora da Graduaçõ em Direito em direito ambiental, civil e processual civil. Universidade de Marília - UNIMAR, São Paulo - Brasil. Lattes: http://lattes.cnpq.br/9183935163895451 E-mail: martinsre31@ @otmail.com
} 
seeks a more detailed study on the right to freedom and its aspects, as well as the adaptations required for development. The first topic is an analysis of the right to freedom, as proposed by the constitutional doctrine, to study the same from the perspective of development, with emphasis on the Decrease Theory, proposed by the philosopher and economist Serge Latouche. In conclusion, it is possible to observe that a critical view of the right to freedom is necessary, because the disseminated vision in the globalized world generates the false notion that economic abundance generates "well-living" and freedom, but, in fact, urges a reassessment of the limits of the fundamental right to freedom and its effective reach in the current economic legal scenario

Keywords: Fundamental right to freedom. Freedom of choice. Speculation in the economic market. Decrease Theory. Serge Latouche.

\section{INTRODUÇÃO}

Na sociedade contemporânea globalizada, a complexidade e interdependência das relações humanas, o crescente aumento de interesses alavancado pelo apelo tecnológico, somado ao reconhecimento da finitude de recursos naturais, exige que o debate acerca do desenvolvimento sustentável não seja esquecido.

É urgente se encontrar opções para o futuro ambiental do planeta que preserve a espécie humana e neste sentido o presente artigo aborda o direito fundamental à liberdade como liberdade de escolha, dentro da mudança de paradigmas que se impõe, exigindo que seja sopesado o direito à liberdade estabelecendo seu limite diante da sustentabilidade, que reclama mudança comportamental.

Com vistas a apresentar propostas de solução para esses conflitos, surgem perspectivas diversas dos conceitos tradicionais de desenvolvimento sustentável, entre elas, a Teoria do Decrescimento proposta por Serge Latouche, que sinteticamente pugna pelo abandono do objetivo do crescimento ilimitado, substituído por uma sociedade que se dedique ao bem viver, trabalhando e consumindo menos. Para que isso seja possível, propõe o incentivo à liberdade inventiva e criativa do imaginário, bloqueada pelo totalitarismo economista e desenvolvimentista.

Para que se admita uma proposta semelhante à da teoria do Decrescimento, é preciso se debruçar um olhar diverso sobre os direitos fundamentais, notadamente a liberdade, estudando-se sua concepção histórico-jurídica tradicional e após, revisitando este conceito, para verificar como a liberdade se enquadra na nossa realidade social face ao comportamento que se desenvolve na economia globalizada. 
A perspectiva de desenvolvimento como liberdade proposta por Amartya Sem se apresenta como um importante paradigma para se discutir o binômio liberdade/sustentabilidade, permitindo que se comprove a visão distorcida deste direito fundamental na sociedade, que precisa ser urgentemente mudado, pra que se dissemine a consciência do indivíduo das consequências de suas escolhas para com o meio ambiente e a preservação da Terra para as futuras gerações.

O presente artigo previne a mudança efetiva de premissas quanto ao meio ambiente, sugerindo-se a importância de verificar mecanismos alternativos, como a Teoria do Decrescimento, apresentada como modelo de proposta para a preservação ambiental para as futuras gerações; ressalta assim a importância de um novo mecanismo de sustentabilidade, que possibilite a existência futura da sociedade, do bem-estar e da qualidade de vida, consolidando liberdades de escolhas baseadas no conhecimento efetivo e no exercício pleno da mesma, como idealizado nos direitos fundamentais.

\section{1 - DIREITO FUNDAMENTAL DE LIBERDADE - COMPREENDENDO UM DIREITO HUMANO DE PRIMEIRA GERAÇÃO}

\section{1-1 - Surgimento e evolução do Direito à Liberdade}

Liberdade é a possibilidade de escolha inerente à pessoa em fazer algo ou não, baseada na sua própria vontade. Ressalte-se que tal direito não é absoluto e não atribui ao indivíduo uma possibilidade ilimitada de fazer qualquer coisa que desejar, mas sim dentro dos parâmetros e limitação da lei. Esse conceito é baseado no princípio da legalidade, que limita as liberdades dos indivíduos. (PINHO, 2002)

Conforme lição de José Afonso da Silva:

O conceito de liberdade humana deve ser expresso no sentido de um poder de atuação do homem em busca de sua realização pessoal, de sua felicidade. (...) Vamos um pouco além, e propomos o conceito seguinte: liberdade consiste na possibilidade de coordenação consciente dos meios necessários à realização da felicidade pessoal. Nessa noção, encontramos todos os elementos objetivos e subjetivos necessários à ideia de liberdade; é poder de atuação sem deixar de ser resistência à opressão; não se dirige contra, mas em busca, em perseguição de alguma coisa, que é a felicidade pessoal, que é subjetiva e circunstancial, pondo a liberdade, pelo seu fim, em harmonia com a consciência de cada um, com o interesse do agente. Tudo que impedir aquela possibilidade de coordenação dos meios é contrário à liberdade.(SILVA, 2003, p. 232) 
Nos dizeres de Norberto Bobbio, os direitos humanos são uma construção histórica, ou seja, são "nascidos em certas circunstâncias, caracterizadas por lutas em defesa de novas liberdades contra velhos poderes, e nascidos de modo gradual, não todos de uma vez e nem de uma vez por todas" (BOBBIO, 1992, p.5).

Por tal razão, a análise específica do contexto onde surgiram os direitos de primeira geração, que inclui o direito à liberdade, tornam especialmente importante para a discussão proposta.

Tomando-se por base a construção da clássica divisão dos direito humanos, tem-se que ela foi inspirada na Revolução Francesa e classificou os direitos humanos basicamente em três gerações: a primeira que corresponde aos direitos civis e políticos (onde se encontra a Liberdade); a segunda que se refere aos direitos econômicos, sociais e culturais (Igualdade) e a terceira que abrange os direitos de solidariedade, o direito ao desenvolvimento, à paz e ao meio ambiente saudável (Fraternidade) (NUNES JUNIOR, TRETTEL, 2008)

A Declaração Francesa e a Constituição Norte Americana foram as primeiras Constituições modernas a contemplaram o direitos de primeira geração, como uma resposta por parte da classe burguesa, então em franca ascensão, em contrariedade ao poder absolutista dos Estados, notadamente na Europa.

Posteriormente surgiram os direito sociais, de segunda geração, como fruto da Revolução Industrial e das condições de trabalho indignas, por pressão dos trabalhadores que, revoltados com as desigualdades materiais que sofriam prende aos empreendedores, exigiam respostas e melhores condições. A plenitude destes direitos, no entanto, somente ocorrem com as constituições do México (1917) e de Weimar (1919).

A afirmação dos direitos de segunda geração, no campo econômico, para sua consolidação exigiu do Estado atuação para promover, de fato, a igualdade entre os cidadãos:

[...]o direito econômico e a atuação do Estado na economia, tal qual consagrados na Constituição Brasileira no Título VII, são fruto de um segundo momento histórico de tratamento dos direitos fundamentais. Ao se tratar de direitos fundamentais de primeira geração, tem-se eminentemente a exigência de que o Estado se abstenha de intervir na esfera individual de cada cidadão. Evolutivamente, o reconhecimento dos direitos fundamentais de segunda geração representou um passo à frente dado pela democracia moderna, demonstrando-se que, na busca da igualdade material, não basta que o Estado se abstenha, devendo este também agir. (NUNES JUNIOR, TRETTEL, 2008, p.275) 
A Declaração Universal dos Direitos Humanos, assinada em 10 de dezembro de 1948 por 48 Nações, foi o primeiro movimento de transposição da legitimidade dos direitos do cidadão, saindo do âmbito limitado dos Estados para o seu reconhecimento no mundo. Tratase de documento considerado como uma premissa histórica de direitos, posto que se consubstanciou no primeiro sistema de princípios fundamentais da conduta humana a ser livre e expressamente aceito, por intermédio dos governos da maioria dos Homens então viventes na Terra (BOBBIO, 1992).

Esse fato marca o início de uma importante fase de história da conquista dos direitos isso porque, a constituição de um documento de ampla aceitação por nações diversas do mundo exerceu grande impacto e significou a afirmação universal e positiva dos direitos humanos.

Reconheceu-se com ela que os destinatários dos princípios contidos na Declaração são todos os Homens; com ela se positiva um processo cujo objetivo final é fazer com que os direitos do Homem não sejam mais apenas proclamados ou apenas idealmente reconhecidos, porém efetivamente protegidos até mesmo contra o próprio Estado, caso este os tenha violado. (BOBBIO, 1992)

Da declaração com um todo é possível se destacar alguns artigos que versam mais especificamente sobre direito à liberdade, cuja transcrição se faz (ORGANIZAÇÃO DAS NAÇÕES UNIDAS, 1948)

Artigo 18. Todo ser humano tem direito à liberdade de pensamento, consciência e religião; esse direito inclui a liberdade de mudar de religião ou crença e a liberdade de manifestar essa religião ou crença pelo ensino, pela prática, pelo culto em público ou em particular.

Artigo 19 Todo ser humano tem direito à liberdade de opinião e expressão; esse direito inclui a liberdade de, sem interferência, ter opiniões e de procurar, receber e transmitir informações e idéias por quaisquer meios e independentemente de fronteiras.

Artigo 20 1. Todo ser humano tem direito à liberdade de reunião e associação pacífica.2. Ninguém pode ser obrigado a fazer parte de uma associação.

Percebe-se que a declaração visa assegurar a liberdade, como direito de todo os Homens tendo em vista diversas circunstâncias, que vão desde a religião, liberdade de opinião e expressão, de associações, entre outros; entretanto, não se verifica, quando da elaboração deste documento seque uma menção a proteção da liberdade de escolha, como 
direito fundamental ao ser humano, para que ele tenha assegurado outros direitos fundamentais à partir do exercício desta liberdade.

Destaca-se, no entanto, que o artigo XXVIII da Declaração, abrange "liberdades" e ressalta que é preciso que se estabeleçam mecanismos eficientes para assegurar que elas sejam respeitadas e plenamente realizadas.

Artigo 28. Todo ser humano tem direito a uma ordem social e internacional em que os direitos e liberdades estabelecidos na presente Declaração possam ser plenamente realizados.

O Brasil é um dos países signatários da Declaração Universal dos Direitos Humanos e nossa atual Constituição abriga seus princípios ao longo de todo o texto normativo. Especificamente no artigo $5^{\circ}$ é possível se observar que à liberdade foram dedicados diversos incisos, IV, VI, XII, XV, XVII, entre outros, com a finalidade de preservar esse direito fundamental; entrementes em nenhum artigo existe referência explícita à liberdade de escolha como um direito fundamental, até porque "escolher" é uma liberdade que somente se exerce quando o indivíduo tem plena consciência de seus direitos, bem como conhece a verdade sobre o que lhe é socialmente oferecido para que exerça escolhas.

Explica-se: exercer escolhas demanda, primeiramente, que o indivíduo tenha o mínimo existencial para que que possa fazê-lo, como acesso a bens que lhe garantam o mínimo digno à sobrevivência. Ademais e em um segundo momento, os bens que são colocados à disposição para exercício da liberdade de escolha, não podem atender somente ao direto de "liberdade" do empreendedor em obter lucro, devem ser ofertados de forma íntegra, dentro dos parâmetros do direito econômico concorrencial, mas observado os reclamos de preservação e reocupação do meio ambiente.

É preciso se dar ciência plena e coerente àquele que exerce escolhas, das consequências que o consumo ilimitado e insaciável pode trazer para o meio ambiente, saúde e qualidade de vida; somente assim, o direito à liberdade de escolha poderia ser efetivamente exercido com status de direito humano fundamental, protegido constitucionalmente, tornando todo Homem responsável pela preservação do planeta e da espécie.

\section{2 - O Direito como agente controlador e favorecedor da liberdade.}

De acordo com Sartre, afirma-se que o Homem está "condenado à liberdade", não existe nenhum determinismo metafísico a lhe estabelecer caminhos; é ele quem os especifica 
e governa. Por essa visão existencialista cabe ao Homem a criação de mecanismos de controle e repressão das liberdades, o que se faz através do Direito, agente regulador da vida comum, essencial para o bem comum. (SARTRE, 1970)

A natureza humana é gregária e moral; com o processo histórico de evolução cultural o Homem, além de interagir com a natureza, passa a valoras as coisas do mundo. Esse processo de moralização, por muito tempo, que perdurou da antiguidade até o final da idade Média, for marcado por ter agregada a moral à religião, sendo o Direito neste contexto, a manifestação da lei com seus mecanismos de controle e repressão. (WOLKMER, 2008)

Atualmente o Direito somente se dedica às condutas morais de maior relevância, com vistas a defesa e proteção dos bens que são altamente valorados pela moral e que devem ser protegidos, para que não fiquem à mercê de violações socialmente intoleráveis.

Por essa análise se pode inferir que liberdade e direito sofreram um processo civilizatório. Nas sociedades o agir humano não é ilimitado, mas controlado pela ação estatal sendo e quanto mais complexa a sociedade, mais complexo será o mecanismo de controle de liberdades.

O Direito, tanto mais complexo e maior, surge então como mecanismo de controle de tensões sociais e dirigismo de condutas, haja vista que, por meio de normas procura modelar a sociedade desejada pelo Estado.

Este caminho é seguido atualmente, inclusive pelo Brasil, como se pode verificar pela Constituição Federal, que estabelece a sociedade almejada, em termos de desenvolvimento preceituando no artigo 170 as diretrizes a seguir, que permeiam a livre inciativa, no entanto, com limites, que são os princípios a serem cumpridos, entre eles, a defesa do meio ambiente.

Nos termos do legislador constitucional, este seria o caminho delineado para a implantação do Bem Comum em meio as múltiplas demandas contemporâneas, que envolvem uma série de "necessidades" geradas pela evolução cultural tecnológica e que, sem dúvida, tem nos distanciado cada vez mais da liberdade no sentido absoluto.

Em termos de liberdade de escolha, uma série de fatores gerados pela sociedade econômica de consumo são determinantes e influenciam diretamente as "escolhas" do indivíduo neste contexto, onde a mesma nem sempre é fruto do exercício do direito fundamental de liberdade, mas sim de um dirigismo imperceptível, incentivado por necessidades, nem sempre reais. 
Em razão disto mais apropriado seria usar-se o termo autonomia, faculdade, prerrogativa de escolha, para explicar as condições atualmente vividas, ao invés de confundir-se com liberdade enquanto direito fundamental.

A noção de liberdade enquanto direito fundamental encontra limites na lei e assim José Afonso da Silva diz ao se referir à liberdade de ação como um direito que se extrai do art. 5, II, CF/1988, que consagra o princípio de legalidade, extraindo-se deste pensamento os parâmetros limitados de liberdade das relações intersubjetivas, que em verdade devem se adequar a comportamento normatizados.

\section{2 - DESENVOLVIMENTO SUSTENTÁVEL $x$ TEORIA DO DECRESCIMENTO}

\section{1- Desenvolvimento sustentável - uma definição em desconstrução}

Paralelamente ao Direito, que como visto, regula condutas, fazendo com que o exercício do direito fundamental à liberdade seja limitado, o desenvolvimento econômico, alavancado pela globalização e sua incessante evolução, traz consigo a idéia de crescimento ilimitado como um valor básico da sociedade; com isto os direitos fundamentais, entre eles a liberdade, conquistados pelo Homem no decorrer da história, vão perdendo sua importância, substituídos pela premissa de Bem-estar social, que seria obtido tendo em vista a possibilidade de consumo.

No entanto, a realidade de degradação ambiental observada no planeta requer seja repensada a definição de desenvolvimento sustentável até então adotada, através de um olhar isento e crítico, que reconheça a inviabilidade do modelo vigente em face da ruína que se verifica no ecossistema.

A Teoria do Decrescimento, proposta pelo filósofo Serge Latouche, em contraposição aos conceitos postos de desenvolvimento sustentável, permite verificar outras propostas para se atingir um ponto de equilíbrio, certo de que o agente humano, exerce papel fundamental à implementação e manutenção do sistema, devendo ele conhecer em plenitude todos os nuances que se apresentam, para que possa exercer seu direito fundamental à liberdade de forma a ser agente ativo neste processo, e não somente uma marionete dos interesses econômicos globais.

A concepção de desenvolvimento surge em um contexto histórico, vista como mudança de paradigma para reparar desigualdades sociais que se observavam desde as 
épocas antigas, onde nações metropolitanas e periferia colonial ocasionavam discrepância entre as minorias ricas e a maioria ainda exausta e atrasada de trabalhadores pobres, o que, guardada as devidas proporções, se mantém até os dias atuais.

Desenvolvimento, dentro deste contexto, é o termo que surge como promessa de uma modernidade inclusiva, com mudanças estruturais neste sistema de desigualdades. (SACHS, 2008)

O fator econômico é crucial no diálogo do desenvolvimento e quanto a ele, desde Aristóteles economia e ética caminhavam interligadas por duas questões de fundo relativas ao problema da motivação humana e avaliação das conquistas sociais; ao longo do tempo, porém, questões logísticas econômicas fizeram com que preponderasse o lucro e a ética ficasse esquecida. Atualmente a reaproximação de ambas, aliadas à política (SEN, 2008, p. 94) desempenha papel fundamental para a tentativa de implementar o desenvolvimento, com redução de desigualdades sociais.

Importante destacar que o crescimento acelerado da economia observado na era moderna, não pode ser confundido com desenvolvimento, na medida em que não assegura liberdades, não é suficiente a propiciar o aumento de empregos, redução de pobreza e nem atenua desigualdades sociais; desenvolvimento exige equidade em termos operacionais, de forma a tornar mais inclusiva a participação dos mais fracos no sistema.

Alia-se a esse conceito o desenvolvimento sustentável e a sustentabilidade ambiental que passam a integrar a dimensão do desenvolvimento e sustentabilidade social.

Historicamente o termo "desenvolvimento sustentável”, apareceu publicamente em meados de agosto de 1979, quando da realização do Simpósio das Nações Unidas sobre a inter-relação existente entre Recurso, Ambiente e Desenvolvimento; naquela ocasião Ignacy Sachs viu retirarem do texto o conceito de ecodesenvolvimento por ele proposto. (RODRIGUES, 2007)

Posteriormente, no relatório "Nosso Futuro Comum" desenvolvido pela Comissão de Brundtland ocorrida em um processo preparatório para a Conferência das Nações Unidas - também chamada de "Rio 92" surgiu efetivamente o termo "desenvolvimento sustentável”. Neste relatório está inserido uma das definições mais difundidas do conceito de desenvolvimento sustentável: "o desenvolvimento sustentável é aquele que atende as necessidades do presente sem comprometer as possibilidades de as gerações futuras atenderem suas próprias necessidades".(ONU, 1987) 
O relatório Brundland faz muito mais do que estabelecer o conceito de desenvolvimento sustentável, ele considera que as políticas ambientais e de desenvolvimento para cumprirem os requisitos da sustentabilidade devem incluir a preservação da paz, o crescimento mas alterando a qualidade deste, bem como remediando os problemas da pobreza e satisfazendo necessidades sociais, abordando os problemas do crescimento populacional e de conservação e reforço da base de recursos naturais, reorientando a tecnologia e gerindo os riscos; assim, reconhece que é necessária a fusão do ambiente e da economia, alicerçados pelas bases governamentais na tomada de decisões.

O conceito de desenvolvimento sustentável deve atender a um duplo imperativo ético que integra a geração atual com as futuras gerações, obrigando-nos a trabalhar com noções diversas daquelas propostas pela economia tradicional, que observa somente o lucro como objetivo precípuo e imediato.

Reconhece que é preciso buscar soluções que eliminem o crescimento selvagem obtido ao custo de elevadas externalidades negativas ambientais e exige estratégias, para propiciar um crescimento benéfico tanto do ponto de vista social como ambiental.

Ignacy Sachs ao estudar o tema propõe cinco pilares para se alcançar o desenvolvimento sustentável:

a) Social, fundamental por motivos tanto intrínsecos quantos instrumentais, por causa da perspectiva de disrupção social que paira de forma ameaçadora sobre muitos lugares problemáticos do nosso planeta;

b- Ambiental, com as suas duas dimensões (os sistemas de sustentação da vida como provedores de recursos e como "recipientes" para a disposição de resíduos);

c- Territorial, relacionado à distribuição espacial dos recursos, das populações e das atividades;

d- Econômico, sendo a viabilidade econômica a conditio sine qua non para que as coisas aconteçam;

e-Político, a governança democrática é um valor fundando e um instrumento necessário para fazer as coisas acontecerem; a liberdade faz toda a diferença (SACHS, 2008, p. 15)

Os requisitos apresentados e basicamente repetidos pela doutrina e em conferências ambientais, demonstram uma necessária mudança de paradigma em relação ao modo pelo qual ocorre a exploração econômica dos bens em relação à sociedades, para que os objetivos 
que derivam do conceito de desenvolvimento sustentável possam permitir a conservação dos recursos naturais e estabelecer o uso racionado destes nas atividades produtivas.

Entre os objetivos do desenvolvimento sustentável estão: - crescimento renovável; mudança de qualidade do crescimento; - satisfação das necessidades essenciais por emprego, água, energia, alimento e saneamento básico; - garantia de um nível sustentável da população; - conservação e proteção da base de recursos; - reorientação da tecnologia e do gerenciamento de risco; - reorientação das relações econômicas internacionais (BARBOSA, 2008.)

Outros doutrinadores que se debruçam sobre o tema da sustentabilidade alertam para as mesmas necessidades, como se pode observar pelas palavras de Henri Acselrad, neste sentido: - a eficiência, antagônica ao desperdício como base material do desenvolvimento, com reflexos da racionalidade econômica sobre o "espaço não-mercantil planetário; a escala, determinante de limites quantitativos para o crescimento econômico e suas respectivas pressões sobre os recursos ambientais; - a eqüidade, articuladora analítica entre princípios de justiça e ecologia; -a auto-suficiência, desvinculadora de economias nacionais e sociedades tradicionais dos fluxos de mercado mundial, como estratégia apropriada para a capacidade de auto-regulação comunitária das condições de reprodução da base material do desenvolvimento; a ética, evidenciadora das interações da base material do desenvolvimento com as condições de continuidade da vida do planeta. (ACSELRAD, 2001).

Percebe-se que atualmente o discurso sobre a necessidade de se atentar para o desenvolvimento sustentável é recorrente, com fito a resgatar a visão ética que a economia perdeu quando se focou somente no lucros, para propiciar um desenvolvimento econômico de longo prazo e eficiente.

Entretanto, alcançar desenvolvimento sustentável, se é que é possível, exige solidariedade diacrônica e sincrônica para as presentes e futuras gerações, importando uma autoalimentação entre diversos sistemas - político, social, econômico, tecnológico, entre outros.

É necessário pensar a questão ambiental além da perspectiva do desenvolvimento tradicional. É preciso compreender um caráter multidimensional do desenvolvimento, bem como da sustentabilidade. Todo processo sustentável tem como fundamento o território como elemento no qual se cristalizam as bases ecológicas e suas identidades culturais. (TYBUSCH, 2011, p. 85) 
O problema reside em se verificar se o planeta suporta a persecução de um desenvolvimento, mesmo que sustentável, sendo importante incluir neste cenário o indivíduo, que deve ser informado de todas as nuances desta produção e exploração ambiental, com discurso ambientalmente correto, para que possa participar ativamente, exercendo liberdade de escolhas.

No cenário atual é recorrente que empresas planejem seus discursos pautados na proposta do desenvolvimento sustentável. Dessa forma, o cidadão ao entabular relações com as mesmas, acredita que está contribuindo para preservar o meio ambiente, as suas próprias necessidades e as das gerações futuras.

O uso do vocábulo gera expectativa de que o produto consumido não representa maiores riscos de aumento da desigualdade social e degradação ambiental e cultural, o que nem sempre corresponde à realidade.

Nesse viés, se propões a análise de um contraponto à teoria do desenvolvimento, partindo-se do referencial teórico da Teoria do Decrescimento, que sugere um paradigma contrário à exploração do meio ambiente e ao discurso do desenvolvimento sustentável, a fim de que seja possível se verificar quando, no campo prático, as ações empresariais são coerentes e quando são um embuste disfarçado, promovendo tão e somente o progresso e o interesse econômico.

\subsection{Teoria do decrescimento - repensar liberdades de escolha}

A globalização e o crescimento ilimitado, tem provocado diversas crises sociais que resultam em catástrofes ambientais e sociais, problemática esta que incentivou o filósofo francês Serge Latouche a desenvolver a Teoria do Decrescimento, que teve como origem o reconhecimento de que o comportamento social em seu anseio ilimitado por crescimento é incompatível com os recursos naturais existentes, gerando crise ambiental.

A sociedade se alicerçou sobre as premissas de acumulação ilimitada. Para Latouche, esse modelo de sistema estaria "condenado" ao crescimento ilimitado perverso e pernicioso; em outras palavras, qualquer fator que ocasione redução ou parada no crescimento, motivaria uma crise de pânico, por receio de crises sociais com redução de empregos e direitos sociais, como saúde, moradia, educação, etc, além da restrição tecnológica, que na atual sociedade de consumo, é inadmissível. (LATOUCHE, 2006) 
A Teoria do Decrescimento propõe que a sociedade abandone o crescimento pelo simples "crescimento" e mude o rumo dos paradigmas sociais equivocados pela ilusão de que a felicidade se assenta na possibilidade de consumo.

Serge Latouche diz que essa ideia de crescimento ilimitado foi alimentada pelos princípios da economia neoclássica tradicional, que via a função social da empresa como a de assumir o papel de proporcionar retorno econômico-financeiro para seus donos ou acionistas. Com isso imaginava-se estar diante de um mecanismo eficiente a contribuir para o desenvolvimento da sociedade nos seus diversos aspectos; ocorre que a premissa desta crença se assentava na suposição que o meio ambiente seria infinito, portanto, comportando o desenvolvimento sem limites almejado pela sociedade. (LATOUCHE, 2006)

Imaginava-se também que este desenvolvimento atenderia os anseios de todas as classes sociais, diminuindo as desigualdades e proporcionando o bem-estar, discurso alardeado convenientemente pelas classes dominantes, mas que não se efetivou na prática; em verdade uma sociedade que tem como premissa o crescimento ilimitado ocasiona, no mínimo três sérios problemas: gera um aumento das desigualdades e injustiças; cria um bemestar largamente ilusório e fomenta uma "antisociedade" onde os ricos ficam isolados devido à sua riqueza. (LATOUCHE, 2006)

Segundo a Teoria do Decrescimento, a expressão desenvolvimento sustentável seria um subterfúgio de plataformas políticas e econômicas, invocado de forma reiterada para convencer a população, mas cujo objetivo único que é a conservação dos lucros, evitandose mudança de hábitos de consumo, cada vez mais crescente da população.

Latouche diz que falar-se em desenvolvimento sustentável como se fosse uma outra forma de se desenvolver seria, no mínimo ingenuidade e na verdade, as propostas neste sentido são antigas e tentam conciliar preservação do meio ambiente com conquistas de dominação econômica, o que tem se mostrado ineficiente. (LATOUCHE, 2006)

Prossegue justificando que o mecanismo de desenvolvimento que vem sendo adotado é ineficiente porque não respeita o tempo de recuperação do meio ambiente e, de forma crítica, noticia que será impossível sem renúncias e ainda ganhando dinheiro, estabelecer compatibilidade sistema industrial produtivista e os equilíbrios naturais, fiando-nos unicamente nas inovações tecnológicas.

Por esses resumidos motivos, já que a Teoria é ampla e não será esgotada neste trabalho, o filósofo sugere que a sociedade necessita entrar em um processo necessário de decrescimento material e de reconsideração sobre o que seria riqueza, baseando-se em 
indicadores efetivamente direcionados à preservação e viabilidade ecológica e de justiça social; seria necessário mudar o paradigma do "bem-ter" para um bem estar vivido.

Latouche alerta que o receio de crises sociais, um dos motivos a justificar o "desenvolvimento", se não for repensado, em caráter urgencial, ocasionará exatamente a crise que se pretende evitar.(LATOUCHE, 2006)

Para alcançar o objeto do decrescimento, o filósofo indica sistemas onde expressa mudanças de comportamento sociais devem ser realizadas para se formar uma sociedade de decrescimento, onde percebe-se que o cidadão, é parte ativa e decisiva do processo, o qual ele deve conhecer, compreender e aderir.

O sistema proposto, sinteticamente, seria dos 8 "Rs", ou seja, oito mudanças interdependentes mínimas para desencadear a formação da sociedade do decrescimento: reavaliar, reconceituar, reestruturar, redistribuir, relocalizar, reduzir, reutilizar, reciclar. (LATOUCHE, 2009)

Verificando-se as críticas do filósofo e o conceito de desenvolvimento sustentável utilizado por discursos políticos e pelas grandes empresas, mormente as multinacionais, a questão se se coloca refere-se ao fato de que o indivíduo, dentro desse contexto é o consumidor direto que recebe propagandas de "produtos", sob a alocação de que seriam "sustentáveis"; entretanto nem sempre é assim. Ou seja, o indivíduuo é levado à falsa impressão de que ao adquirir o produto está "colaborando" com a preservação do meio ambiente, mas na realidade nada mais se tem do que o emprego do vocábulo "desenvolvimento" como sinônimo de crescimento econômico, ou seja, visa-se o progresso a qualquer custo.

Neste sentido, a verdade sobre a degradação ambiental é relativizada por interesses econômicos, em detrimento dos direitos fundamentais e à saúde humana, o que certamente pode oferecer risco à vida humana na Terra.

Diante disto, como se imaginar que os indivíduos exercem plenamente seu direito à liberdade? Será que, na falta do mínimo existencial que se observa nas nações mais pobres e mesmo nos países mais desenvolvidos e nas ilusões "vendidas" de progresso ilimitado, o indivíduo efetivamente tem "liberdade" de escolher? Escolheria o caos para a espécie humana, se efetivamente tivesse consciência de onde essa busca frenética pelo "ter" pode levar a raça humana? 


\section{3 - REVISITANDO O DIREITO FUNDAMENTAL À LIBERDADE - OS LIMITES PARA O DESENVOLVIMENTO}

\section{Relativização dos direitos fundamentais e preservação ambiental}

Direitos fundamentais são relativos e devem conviver e ser interpretados como uma unidade harmônica, não existindo hierarquia entre eles.

No que concerne ao meio ambiente, a Constituição Federal em seu artigo 225 atribuiu status de direito fundamental. O nosso texto incorporou o conceito proveniente de declarações e tratados internacionais do desenvolvimento sustentável, tendo como um dos mais importantes teóricos Ignacy Sachs, que preceitua desenvolvimento sustentável sob uma ótica econômica, ambiental e social. (SACHS, 2008)

Já relativamente à liberdade, para que ela se exerça com plenitude é preciso se supor um nível mínimo de igualdade, que deve ser garantido por mecanismos estatais de regulação social.

O Estado, enquanto organização estatal alicerçada no paradigma da liberdade, incentiva a intensificação e expansão das relações comerciais que, gradativamente, passaram a adquirir contornos cada vez mais globalizados. As próprias pressões do mercado econômico alavancaram avanços significativos em vários setores como comunicação, produção e transporte e intensificaram a construção de um espaço mundial cada vez mais integrado, sedimentando a globalização. (STELZER, 2010).

Ocorre que a globalização, apesar de apresentada com seus caracteres positivos, produz inúmeros efeitos colaterais negativos motivados pelos impactos das ações do homem sobre a natureza, transcendendo fronteiras e espraiando riscos por toda a Terra. A devastação da Mata Atlântica brasileira e da Amazônia, com danos de extensão incalculáveis e extinção de ecossistemas inteiros, são exemplos dos danos que somos capazes de praticam em detrimento do meio ambiente.

A preocupação com discursos ambientais, tendo em vista o reconhecimento de que o Homem pode destruir o planeta, surgiu a partir da década de 80 do século passado, reclamando que as questões relacionadas aos indivíduos, seus direitos e interesses, quer de natureza individual ou coletiva, passassem a ser observadas por outro viés, sendo necessário se "revisitar" o conceito de liberdade. 
Neste sentido, no limiar de uma nova era, o paradigma da liberdade deve ser relativizado e progressivamente enfraquecido pela coabitação com um novo paradigma axiológico do Direito: o paradigma da Sustentabilidade. (CRUZ, BODNAR, 2011)

Todavia, o Estado deve intervir o mínimo possível na vida dos membros da Sociedade, assegurando autonomia privada das pessoas - a liberdade. Individualismo, livre arbítrio, propriedade privada, livre iniciativa, livre concorrência, autorregulação do mercado, são todas noções que exsurgem do paradigma axiológico da liberdade e permeiam o Estado liberal e seu sistema jurídico.

Há que ponderar, entretanto, que o discurso liberal sempre foi demagógico e se refere à sociedade, como se os direitos proclamados e reconhecidos politicamente fossem aplicados para a comunidade humana por inteiro. Irrealidade, posto que uma gama de direitos apregoados pelo Estado tem "vigência tão-somente parcial, e em proveito da classe que efetivamente os podia fruir" (BONAVIDES, 2011 p. 44)

Desta forma a liberdade alardeada pela máquina estatal é meramente formal, mas na prática potencializa e multiplica desigualdades, fomenta a dominação e a exploração da classe economicamente dominante sobre a classe operária; entretanto o discurso "vendido" nos meios de comunicação globalizados, investem nas promessas do "bem-ter" que escravizam os interesses do classe operária, a qual, aquém das condições econômicas e culturais suficientes de discernimento, absorve a idéia e vive em situação de exploração semelhante à ocorrida durante a Revolução Industrial, guardada as devidas proporções, acreditando que está exercendo seu direito de liberdade.

Por isso é necessário se analisar o direito fundamental de liberdade tendo em vista o paradigma axiológico da Sustentabilidade na sociedade, que deve avaliar o problema da distribuição e do enfrentamento dos riscos fabricados pela modernidade.

Serge Latouche crítico fervoroso do consumismo produzido e induzido, defende o que denomina, conforme já dito, de decrescimento sustentável. Afirma que o ecossistema global não tem capacidade de dar sustentabilidade ao crescimento econômico, como vem se pugnando, partindo-se da premissa básica de que os recursos naturais são limitados.

No entanto, o discurso político e empresarial, insiste em reescrever os conceitos de desenvolvimento sustentável, quando deveria em verdade revisitar o direito à liberdade de escolhas dos indivíduos, diante da necessidade de preservar o meio ambiente.

Veja-se que, em nome de se manter o conceito desenvolvimento sustentável, a ONU, em 2015, lançou 17 objetivos e 169 metas a serem cumpridos para uma preservação 
ambiental, denominados por "Transformando Nosso Mundo: A agenda 2030 para o desenvolvimento sustentável" que parecem um slogan de campanha política. (ONU, 2015)

A questão pragmática que se propõe é a verificação de viabilidade destes objetivos, sendo que aqueles que detém o capital organizam-se e às suas atividades empresariais de tal forma, que ao indivíduo não é possível mensurar os riscos aos quais se está, de fato, exposto.

A liberdade, neste contexto, somente é utilizada pelo empreendedor que, normalmente observa somente seu objetivo de lucro, pouco se importando com os danos ao meio ambiente e aos indivíduos em geral. Nesse viés, tem-se que diversas empresas que empregam no seu discurso o desenvolvimento sustentável, insistindo que suas atividades respeitam a sustentabilidade, na realidade, não se preocupam com nenhuma das facetas desta.

Vejamos exemplos recentes de tragédias ambientais que se repetem ao redor do mundo:

2) Na mesma Amazônia, na parte que fica no Equador, mais de 30 mil povos indígenas estão em guerra contra a Chevron pelo que já está sendo chamado de maior desastre ambiental da história da humanidade. Em 2011, a Suprema Corte do Equador ordenou a empresa a pagar mais de 9 bilhões de dólares para compensar as vítimas e para limpar suas terras. Mas a corporação recorre sempre e se vale de um recurso muito usado pelas transnacionais: quando acontece um problema num país elas tiram de lá sua sede. A situação está tão crítica que já há na internet uma petição de ajuda às "vítimas do Equador". (GONZALES, 2016)

Percebe-se que, embora na atualidade a expressão desenvolvimento sustentável seja uma recorrente em plataformas políticas e empresariais, inclusive na ONU, na realidade não existe a apregoada conciliação entre progresso e o respeito à sustentabilidade; o que observamos é um desenvolvimento insustentável, se que concretiza na busca desenfreada por lucro, mascarada por discursos falaciosos.

Assim, forçoso se reconhecer que, no que tange à preservação ambiental, o mundo se encontra em recessão sendo imprescindível, para que saiamos dela enquanto a ainda há tempo, que a economia exista em função da vida e não ao contrário. É preciso mudar paradigmas, mas como operar se as pessoas "livremente" se submetem a essa situação e acreditam estar vivendo a plenitude da liberdade. Neste sentido Segue Latouche:

"Big Brother é anônimo, por outro lado, a servidão dos sujeitos é hoje mais voluntária que nunca, pois a manipulação da publicidade comercial é infinitamente mais insidiosa que a da propaganda política. Como nestas condições enfrentar "politicamente" a "megamáquina"? (LATOUCHE, 2009, p. 127) 
Reconhecidamente somente é possível uma mudança de rumos à partir da mudança da perspectiva global e neoliberal em que se está inserido. Propostas, como as realizadas na Teoria do Decrescimento devem ser consideradas, porque permeiam uma visão diferenciada sobre as necessidades humanas e o bem viver; propõe que seja respeitado o direito de liberdade tolhido ao cidadão atualmente, já que a ele é dado conhecer somente o que interessa às grandes detentoras dos mercados econômicos e políticos.

Para que seja viável implementar tal consciência sobre sustentabilidade e seja viável seu cumprimento, outro programas precisam ser apresentados, possibilitando alternativas sociais; devem ser abolidas legislações, normativas ou regulamentações que possuam disposições contrárias aos interesses da coletividade global, uma vez que assim não haverá instrumento jurídico legitimando práticas dessa estirpe.

É preciso desenvolver-se a consciência ecológica, por intermédio do trabalho conjunto de diversos sistemas substituindo-se a mercantilização de conhecimentos e da própria vida, e a visão de a curto prazo típica do mundo atual, a fim de que se possa proteger não apenas a geração presente mas também as futuras gerações.

As propostas apresentadas pela Teoria do Decrescimento, podem conter instrumentos eficientes, se analisadas e utilizadas com sem preconceitos e com as devidas cautelas. Vejase que a primeira proposição nela contida é a reavaliação, que implica na verificação dos valores preconizados na sociedade, porque atualmente o sistema tem determinado os valores da sociedade, quando deveria ser o inverso (LATOUCHE, 2009)

No mesmo sentido o filósofo propõe também a relocalização, com implementação de alternativas para se fomentar o desenvolvimento do local em primeiro lugar; esta proposta é fruto da crítica à globalização, que fomenta a exploração por parte das transnacionais em detrimento do desenvolvimento local, ou seja, a globalização atenderia aos interesses dos grandes empreendedor e das grandes nações, alimentando desigualdades e impedindo o desenvolvimento das nações mais pobres, sempre exploradas neste sistema. (LATOUCHE, 2009)

Nas palavras de Serge Latouche, ocorre exploração em âmbito mundial, sendo que as grandes potências abusam dos que tem menos condições no mercado global, destruindo perspectivas que a economia local poderia ter e sacrificando possibilidades de desenvolvimento de questões sociais, quais sejam, a melhoria da qualidade de vida e, consequentemente aumento da efetividade e eficácia de direitos fundamentais daquela 
determinada sociedade. Os locais perdem o sentido em prol da mundialização. (LATOUCHE, 2009)

Destas considerações se pode perceber que é preciso repensar novos caminhos para se preservar o planeta, inclusive para as futuras gerações, que ultrapasse o mero discurso. Em matéria de direitos isso exige também um novo olhar sob os direitos fundamentais, equilibrando-se os mesmos.

A liberdade, como direito fundamental, deve ser balizada pela sustentabilidade, porque agindo como escravos de nossos interesses ilimitados não teremos como sobreviver. A recessão planetária em matéria ambiental exige que se observe na prática um desenvolvimento sustentável, e as ciências naturais devem ser atores conjuntos, descrevendo o que é preciso e necessário, para um mundo sustentável; neste conjunto de atores compete às ciências sociais a articulação das estratégias de transição rumo a este caminho; ou seja, precisamos revisitar nossos direitos fundamentais e orientar nossas liberdades.

Instrumentos e posições da definição dos riscos tornam-se posições-chave em termos sociopolíticos, para se evitar o caos. Não se pode esquecer que riscos ambientais não deferem privilégios e não respeitam fronteiras; têm caráter universal e transnacional. Neste sentido, aqueles que abusam de suas liberdades conquistadas por posição econômica ou política, produzem e lucram, cedo ou tarde, acabarão por sendo alcançados pelas consequências de destruição ao meio ambiente.

Diante deste cenário propostas como a teoria do decrescimento, podem ser analisadas como alternativas, já que reconhecidamente a Sustentabilidade é uma necessidade inarredável da própria humanidade e não da natureza - independente das ações do homem, a natureza seguirá existindo.

Apesar de parecer um prognóstico pessimista, o fato é que, a prosseguir a exploração desarrazoada da natureza pelo Homem, para cumprir seus caprichos, a espécie humana se coloca deliberadamente em risco ao extremo - em risco de extinção; no futuro próximo permeia a humanidade o risco de ter que enfrentar escassez e dificuldade de sobrevivência em razão das da profundas mudanças nas condições ambientais que ocorrerão para sustentar o atual modelo civilizatório.

Sergue Latouche, ao preconizar a teoria do decrescimento:

Em suma, o processo econômico real, diferentemente do modelo teórico, não é um processo puramente mecânico e reversível; de natureza antrópica ele se desenrola numa biosfera que funciona num empo marcado pela flecha do tempo. Disso decorre para Nicholas Georges-cu-Roegen, a impossibilidade de 
um crescimento infinito num mundo finito e a necessidade de substituir a ciência econômica tradicional por uma bioeconomia, sou seja, pensar a economia no seio da biosfera. Por isso é que o termo "decrescimento" foi empregado em francês para intitular uma de suas coletâneas de ensaios. (LATOUCHE, 2009, p. 15/16)

Os desejos do Homem devem reavaliados e ele precisa deixar de imaginar que está destinado a explorar e dominar os recursos naturais, compreendendo que ele é uma espécie, dentre as muitas espécies que fazem parte da natureza; o que o diferencia é somente a racionalidade e consciência, o que lhe impõe o dever ético de zelar pelos bens naturais.

As sociedades em geral precisam rever os valores que até então reconheciam como fundamentais, o que deve ser feito não somente sob o aspecto individual, político ou territorial, mas pelo prisma da humanidade como um todo.

A incorporação de padrões de conduta favoráveis ao desenvolvimento sustentável deve ser a grande preocupação dos Estados modernos. Neste contexto é preciso se observar que o direito à liberdade deve resguardar uma reciprocidade com as condutas que a sociedade habitualmente, costumeiramente, compreende como corretas, porque é desta junção (moral, legal, normal) que demonstramos conceitualmente ser o critério objetivo para o legislador balizar sua ação normativa, pertinente com um quadro de valores socialmente necessário à preservação do meio ambiente.

Sob esta ótica o comportamento social não está dissociado da tentativa de se estabelecer condutas que atendam os fins sociais mas que, concomitantemente, não estabeleçam a negação da individualidade e vontade real do homem na sociedade; destarte a existência de normas de manutenção das condições naturais e artificiais de sociabilidade não extenua a existência da liberdade humana enquanto figuração da autonomia que a subjetividade contém. Pelo contrário, permeiam um novo paradigma do agir humano frente à liberdade, deixando de lado a sua redução a mero exercício de consumo e acúmulo.

\section{2 - A expressão individual da redução da liberdade}

A matriz neoliberal que se infere da dinâmica capitalista faz referência a uma liberdade individual que estaria diretamente relacionada pela forma que indivíduo produz e consome. (SEN, 2017) 
Para o mesmo autor, entretanto, a miséria e a fome permeiam as sociedades, desde aquelas consideradas desenvolvidas e com economia sólidas, quanto nas nações subdesenvolvidas.

A miséria crônica e a fome, ou seja, a pobreza econômica estão diretamente relacionadas à ausência de liberdade, porque roubam das pessoas o direito de saciar as necessidades mais básicas como a liberdade de saciar a fome, de obter uma nutrição satisfatória ou remédios para doenças tratáveis, a oportunidade de vestir-se ou morar de modo apropriado, de ter acesso à água tratada ou saneamento básico.

Com a exacerbação da individualidade, a busca do individualismo e egocentrismo se acentuou, radicalizando assim a subjetividade e criando a sugestão de que o mundo é atômico e de que o indivíduo contém em si e para si a opção absoluta de liberdade e desenvolvimento, tão ilimitado quanto sua intenção de crescer. Esse tipo de comportamento é incentivado pela ideologia capitalista neoliberal e é criticado ao Serge Latouche, quando diz:

Nossa sociedade amarrou seu destino a uma organização baseada na acumulação ilimitada. Esse sistema está condenado ao crescimento. Quando há desaceleração o parada do crescimento, em a crise ou até o pânico. Reencontramos o "Acumulem! acumulem! Pois essa é a lei e os Profetas do velho Marx. Tal necessidade faz do crescimento uma "camisa de força" ( LATOUCHE, 2009, p. 17)

A idéia de uma liberdade individual alimentada convenientemente pelo mercado político e econômico motiva a perda da dimensão coletiva se torna um empecilho real à execução de medidas sustentáveis e que tenham como objetivo uma cooperação social, isto porque sobrepõe o interesse individual às relações sociais e às metas coletivas cujo escopo seja um benefício transindividual.

Para que seja possível se implementar mecanismos que revisitem as noções de sustentabilidade, como, por exemplo, as propostas da Teoria do Decrescimento, suscitadas neste trabalho, a visão da liberdade reduzida ao aspecto da individualidade se impõe como um sério entrave.

A proposta de execução de atividades que sejam para interesse do bem coletivo, como o é o meio ambiente, esbarra na referência individualista cujo interesse é singular e limitado pela busca imediatista e utilitária do retorno urgente, mensurado, basicamente, a partir da ideia de desenvolvimento meramente econômico, em que a postura sustentável nem sempre é uma resposta viável. 
Ademais retome-se à ideia inicial de que a liberdade depende da produção e consumo e que esta visão já se encontra arraigada no imaginário psicossocial dos indivíduos, se compreende a árdua tarefa de conscientização da necessidade urgente de mudanças de paradigmas comportamentais na área ambiental.

O cenário apresentado demonstra a dificuldade de se propor mecanismos que equilibrem o binômio liberdade/sustentabilidade; por certo alcançar este objetivo, necessita mudanças comportamentais, sendo indispensável a participação do sistema jurídicos de indicação de condutas reais, segundo as quais seria possível conciliar a consciência com liberdade para implementar mudanças reais imperativas no momento histórico ambiental hodierno de degradação.

Entretanto, observadas as frustradas promessas modernas de liberdade reduzidas à condição individual de produção e consumo, o Direito tem visto também a liberdade institucional do Estado ser mitigada, em razão dos interesses e necessidade econômicas dos Estados. Países como o Brasil, denominados emergentes, se adotarem propostas severas em relação ao meio ambiente e que desagradem às grandes empresas mundiais, sofrerão redução de investimentos, o que não convém aos interesses econômicos e políticos da Nação.

Assim, liberdade individual e social e ações efetivas para encontrar novos rumos em defesa da sustentabilidade ambiental, restam à mercê da benevolência dos resquícios de cidadania e consciência dos indivíduos, diante dos apelos promovidos pelos agentes econômicos inclusive, no ideário individual humano.

\section{CONCLUSÃO}

A obtenção dos direitos fundamentais pelo homem representa uma grande conquista no processo de desenvolvimento das nações. Liberdade, responsabilidade e ética, permeiam um entendimento complementar para a concretização dos direitos humanos.

Desenvolvimento sustentável, expressão fruto do início da preocupação humana com a preservação ambiental, traduz anseio de garantias fundamentais complementares, uma vez que o direito ao desenvolvimento pressupõe o direito ao meio ambiente equilibrado e saudável. Com a inclusão na Constituição Federal desses direitos, os mesmos passam a ter status de direitos fundamentais.

A força do desenvolvimento econômico, no entanto, permeia a exploração dos recursos naturais, apesar do discurso demagógico do desenvolvimento sustentável; o 
interesse exclusivo de lucro e expansão prepondera e as pessoas são levadas a consumir e trabalhar, baseadas em falsas premissas de liberdade, gerando uma servidão voluntária.

A idéia de uma liberdade individual é, neste contexto, convenientemente alimentada pelo mercado político e econômico para o consumo ilimitado e motiva a perda da dimensão coletiva, o que se torna um empecilho real à execução de medidas sustentáveis e que tenham como objetivo uma cooperação social, porque sobrepõe o interesse individual às relações sociais e às metas coletivas cujo escopo seja um benefício transindividual.

A Teoria do Decrescimento, sugere um paradigma contrário à exploração do meio ambiente e ao discurso do desenvolvimento sustentável, afirmando que ele esconde embuste, que promove o progresso e o interesse econômico e propondo mudanças radicais de comportamento denominadas por 8 "Rs", ou seja, oito mudanças interdependentes mínimas para desencadear a formação da sociedade do decrescimento: reavaliar, reconceituar, reestruturar, redistribuir, relocalizar, reduzir, reutilizar, reciclar..

É preciso se revisitar o direito à liberdade, que deve resguardar uma reciprocidade com as condutas e um quadro de valores socialmente necessário à preservação do meio ambiente. A incorporação de padrões de conduta favoráveis a sustentabilidade deve ser a grande preocupação dos Estados modernos, o que nem sempre ocorre, porque há interesses políticos e econômicos envolvidos.

A liberdade, como direito e observada sob o aspecto da sustentabilidade, representa a capacidade crítica do indivíduo existir e se orientar na sociedade em relação as atividades institucionais, reconhecendo seus direitos e necessidades e firmando responsabilidades objetivas cujo sentido atinja à universalidade, deixando de observar somente desejos e escolhendo novos rumos ambientais que vislumbrem contexto seguro e possível para as gerações futuras.

A necessidade de se assegurar um mundo ambientalmente sustentável deve ultrapassar as barreiras dos Estados; não se pode mais pensar em desenvolvimento ilimitado, o que é um retrocesso. Há que se prospectar mecanismos alternativos que reconstruam a aliança entre o Homem e a natureza para que possamos continuar a existir.

\section{REFERÊNCIAS}

ACSELRAD, Henri e LEROY, Jean P. Novas premissas da sustentabilidade

democrática. Revista Brasileira de Estudos Urbanos e Regionais, 1, 1999. Disponível 
emhttp://www.educacaoambiental.pro.br/victor/biblioteca/AcselradLeroyNovasPremissas. pdf acesso em 18 de out. 2017

BARBOSA, Gisele Silva; in O desafio do desenvolvimento sustentável. Disponível em:bhttp://www.fsma.edu.br/visoes/ed04/4ed_O_Desafio_Do_Desenvolvimento_Sustenta vel_Gisele.pdf - acesso em 08 dez 2017

BOBBIO, Norberto. A era dos direitos. Tradução de Carlos Nelson Coutinho. Rio de Janeiro: Campus, 1992.

BONAVIDES, Paulo Bonavides. Curso de Direito Constitucional http://www.stf.jus.br/arquivo/biblioteca/novasaquisicoes/2011-06/904548/sumario.pdf acesso em 12 de julho. 2017/

. Do estado liberal ao estado social. 10. ed. São Paulo: Malheiros, 2011

DECLARAÇÃO UNIVERSAL DOS DIREITOS HUMANOS. Disponível em https://www.unicef.org/brazil/pt/resources_10133.htm> acesso 14 julho 2018.

GONZALES, Amélia. Teoria do decrescimento pode ser solução para desastres socioambientais que não param de acontecer? http://g1.globo.com/natureza/blog/novaetica-social/post/teoria-do-decrescimento-pode-ser-solucao-para-desastressocioambientais-que-nao-param-de-acontecer.html acesso 16 julho 2018

HABERMAS, J. O Futuro da Natureza Humana: a caminho de uma eugenia liberal? 2.ed. Trad. Karina Jannini. São Paulo: Martins Fontes, 2010

LATOUCHE, Serge. O desafio do Decrescimento. Trad. Antonio Viegas. Lisboa. Instituto Piaget, 2206

: Pequeno Tratado do Decrescimento Sereno. Trad. Cláudia

Berliner. São Paulo. Editora WMF Martins Fontes Ltda, 2009

NUNES JUNIOR, Vidal Serrano, TRETTEL, Daniela Batalha. Limites à publicidade comercial e proteção de direitos fundamentais. Revista de Direito Constitucional e Internacional. São Paulo, ano 16, vol. 63, p. 270-284, abril-junho 2008.

ONU. Disponível em https://nacoesunidas.org/acao/meio-ambiente/ http://www.un.org/documents/ga/res/42/ares42-187.htm - acesso em 14 julho 2018

ONU: Agenda 2030. Disponível em ttps://nacoesunidas.org/pos2015/agenda2030/ - acesso 19 julho 2018

PINHO, Rodrigo César Rebello. Teoria geral da constituição e direitos fundamentais. 3.ed. rev. São Paulo: Saraiva, 2002.

RODRIGUES, Jacinto. Crescimento, decrescimento sustentável e desenvolvimento ecologicamente sustentável. http://www.africanos.eu/ceaup/uploads/WP_2007_03.pdf acesso 15 julho 2018. 
SACHS, Ignacys. Caminhos para o desenvolvimento sustentável. 2.ed. Rio de Janeiro: Garamond, 2002.

Garamond, 2008

Desenvolvimento: includente, sustentável, sustentado. Rio de Janeiro:

SARTRE, Jean-Paul. O Existencialismo é um humanismo. Trad. Rita Correia Guedes. Paris: Nagel, 1970.

SEN, Amartya. Desenvolvimento como liberdade. São Paulo . Companhia de Bolso. Editora Schwarcz Ltda, 2017.

Schwarcz Ltda, 2008.

Sobre Ética e Economia. São Paulo: Companhia das Letras. Editora

SILVA, José Afonso da. Curso de direito constitucional positivo. 22.ed. rev. atual. São Paulo: Malheiros, 2003. p.232

STELZER, Joana. O fenômeno da transnacionalização da dimensão jurídica. In:

CRUZ, Paulo Márcio; STELZER, Joana (Org.). Direito e transnacionalidade. Curitiba: Juruá, 2010.

TYBUSCH, Jerônimo Siqueira. Sustentabilidade multidimensional: Elementos reflexivos na produção da técnica jurídico-ambiental. Tese (doutorado) Universidade Federal de Santa Catarina, Florianópolis, 2011.

WOLKMER, Antonio Carlos (org.). Fundamentos de História do Direito. 4. ed. atual. Belo Horizonte: Del Rey, 2008.

Trabalho recebido em 02 de abril de 2019

Aceito em 05 de dezembro de 2020 